\title{
Pharmacologic pupil dilation as a predictive test for the risk for intraoperative floppy-iris syndrome
}

\author{
Alessandra Casuccio, BS, Giovanni Cillino, MD, Carlo Pavone, MD, Emanuela Spitale, MD, \\ Salvatore Cillino, MD, PhD
}

PURPOSE: To evaluate the effect of $\alpha 1$-adrenergic receptor antagonists ( $\alpha 1$-ARAs) on pupil diameter and determine whether the diameter predicts intraoperative floppy-iris syndrome (IFIS).

SETTING: Ophthalmology Section, Palermo University, Palermo, Italy.

DESIGN: Prospective cohort study.

METHODS: Male outpatients taking tamsulosin, $\alpha_{1}$-ARAs, or no $\alpha_{1}$-ARAs having phacoemulsification were recruited. Pupils were measured 1 month preoperatively, immediately preoperatively, and postoperatively under mesopic low (0.4 lux) and high (4.0 lux) illumination after pharmacologic dilation. The IFIS severity was graded.

RESULTS: Each group comprised 50 patients. Pharmacologic dilation in both $\alpha_{1}$-ARA groups was statistically significantly less than in the no $\alpha 1$-ARA group 1 month preoperatively, immediately before surgery, and postoperatively $(P=.001, P<.0005$, and $P<.0005$, respectively). The IFIS incidence differed significantly between the tamsulosin and other $\alpha_{1}$-ARA groups and the no $\alpha 1$-ARA group $(P<.0005$ and $P=.017$, respectively) and between the tamsulosin group and the other $\alpha 1$-ARA group $(P=.027)$. On regression analysis, the hazard ratio for overall IFIS incidence was 3.8 in the other $\alpha_{1}$-ARA group $(P=.012)$ and 10.1 in the tamsulosin group $(P<.0005)$. Pupil size was inversely related to IFIS incidence and severity $(P<.0005)$. A dilated pupil of $7.0 \mathrm{~mm}$ or smaller had $73 \%$ sensitivity and $95 \%$ specificity for predicting IFIS ( $P=.0001)$.

CONCLUSIONS: Pupil dilation was inhibited by $\alpha_{1}$-ARAs, in particular tamsulosin. For a pupil $7.0 \mathrm{~mm}$ or smaller, the risk for IFIS existed regardless of $\alpha_{1}$-ARAs treatment, which surgeons should take into consideration.

Financial Disclosure: No author has a financial or proprietary interest in any material or method mentioned.

J Cataract Refract Surg 2011; 37:1447-1454 @ 2011 ASCRS and ESCRS

Intraoperative floppy-iris syndrome (IFIS) was first described by Chang and Campbell in $2005^{1}$ when patients using systemic $\alpha_{1}$-adrenergic receptor antagonists $\left(\alpha_{1}\right.$-ARAs) were noted to have an increased risk for iris complications during phacoemulsification. The clinical definition of this small-pupil syndrome is a triad of intraoperative observations, including floppy iris stroma that surges and billows to normal intraoperative fluidics, prolapse of iris stroma through surgical incisions despite well-constructed wounds, and progressive intraoperative miosis with standard preoperative dilation. ${ }^{1,2}$ Two additional characteristics often accompany IFIS; that is, poor preoperative pupil dilation and reduced motility of the pupil margin. The extent of the syndrome's clinical presentation varies widely, ranging from mild, with a fluttering iris only, to more severe cases that feature the complete triad of signs. ${ }^{3}$ The latter involves a high rate of intraoperative complications, such as iris trauma, zonular dehiscence, posterior capsule rupture, and vitreous loss, as well as postoperative complications, including intraocular pressure (IOP) elevation and cystoid macular edema (CME). ${ }^{1,2,4}$

A poorly dilating pupil is not an uncommon finding during cataract surgery and may have various causes, including glaucoma, diabetes, and pseudoexfoliation, while iris prolapse into the phaco tunnel can be caused by elevated IOP. ${ }^{5}$ However, in IFIS patients, the 
clinical characteristics of the iris during cataract surgery typically differ, mainly due to the hypotonically fluttering iris during irrigation/aspiration (I/A). ${ }^{5}$

Systemic $\alpha_{1}$-ARAs have become accepted as firstline therapy for benign prostatic hyperplasia $(\mathrm{BPH})$ and lower urinary tract symptoms, ${ }^{6,7}$ which are prevalent in the elderly male population. Because of their nonselectivity, the $\alpha_{1}$-ARAs alfuzosin, doxazosin, and terazosin also inhibit vasculature smooth-muscle contraction, leading to an increased incidence of orthostatic hypotension. ${ }^{8}$ Tamsulosin, in comparison, has up to 20 times the affinity for the $\alpha_{1}$-A receptor subtype ${ }^{1,8-10}$ and improves urinary outflow with minimum effect on vasculature smooth muscles. Although IFIS may have a multifactor etiology, systemic treatment with an $\alpha_{1}$-ARA seems to play a pivotal role. $^{11,12}$ The association between tamsulosin and IFIS has been confirmed in numerous studies, $5,13-15$ as has the fact that IFIS may occur in patients taking other $\alpha_{1}$-ARAs. ${ }^{11,13,16-20}$ In the 2008 American Society of Cataract and Refractive Surgery (ASCRS) IFIS survey, ${ }^{21} 95 \%$ of experienced surgeons reported that systemic treatment with the $\alpha_{1}$-ARA tamsulosin makes cataract surgery more difficult and leads to higher rates of complications. Therefore, it would be helpful to predict preoperatively which patients are at risk. . $^{3,8}$

Rather than regarding IFIS as a rare, unexpected, and unpredictable syndrome attributed to 1 drug, IFIS predisposition should be predictable via careful evaluation of pupil size behavior. A recent study by Chen et al. ${ }^{22}$ found that a preoperative dilated pupil diameter smaller than $6.5 \mathrm{~mm}$ was significantly associated with an increased incidence of IFIS in patients taking tamsulosin.

This prospective cohort study attempted to predict IFIS risk and severity by pupil size in male patients having cataract surgery. It assessed the influence of various $\alpha_{1}$-ARAs on pupil diameter under mesopic conditions and after pharmacologic dilation. It then analyzed the predictive power of these parameters with respect to IFIS onset.

Submitted: January 12, 2011.

Final revision submitted: February 22, 2011.

Accepted: February 24, 2011.

From the Department of Experimental Biomedicine and Clinical Neuroscience (Casuccio, G. Cillino, Spitale, S. Cillino), Ophthalmology Section, and the Department of Internal Medicine (Pavone), Urology Section, University of Palermo, Palermo, Italy.

Corresponding author: Salvatore Cillino, MD, PhD, Dipartimento di Biomedicina Sperimentale e Neuroscienze Cliniche-Sezione di Oftalmologia, Università di Palermo, Via Liborio Giuffrè 13, 90127 Palermo, Italy. E-mail: cillino@unipa.it.

\section{PATIENTS AND METHODS}

Consecutive male cataract patients having phacoemulsification at the Ophthalmology Section, University of Palermo, Italy, from June to December 2009 were prospectively recruited. The study adhered to the tenets of the Declaration of Helsinki, and the research protocol received institutional review board approval. Patients were thoroughly informed about the procedures and provided written consent.

Three groups were evaluated: patients taking tamsulosin for at least 1 year, patients taking another $\alpha_{1}$-ARA for at least 1 year, and control patients taking no $\alpha_{1}$-ARA. The inclusion criterion for the no $\alpha_{1}$-ARA controls was age match. The exclusion criteria were diabetes, glaucoma, pseudoexfoliation syndrome, previous ocular trauma, use of eyedrops other than artificial tears, a history of iridocyclitis, iris neovascularization, previous eye surgery, traumatic cataract, zonular dialysis, and inability to give informed consent. Medication histories for all patients were recorded. The data-collection team was masked to patient-group affiliation.

\section{Pupil Measurement}

One month before surgery, 2 pupil measurements were taken using a computerized infrared pupillometer (Sirius, Costruzione Strumenti Oftalmici) under mesopic low (0.4 lux) and mesopic high (4.0 lux) illumination. The pupil was then dilated with 2 drops of tropicamide $0.5 \%$-phenylephrine hydrochloride $10 \%$ (Visumidriatic Fenilefrina), and 20 minutes later a third measurement was taken under mesopic high (4.0 lux) conditions.

Approximately 15 to 20 minutes before scheduled surgery, mydriasis was obtained by instillation of 2 drops of tropicamide $0.5 \%$-phenylephrine hydrochloride $10 \%$, repeated once after 5 to 10 minutes. This was followed after an additional 10 minutes by 3 drops of lidocaine hydrochloride $4 \%$ (Alfa Intes). No topical atropine or cyclopentolate was used before surgery. The surgeon performed the fourth and fifth measurements using calipers immediately before and at the conclusion of surgery.

\section{Surgical Technique}

The same experienced surgeon (S.C.) performed all surgeries. A temporal $2.75 \mathrm{~mm}$ near-clear corneal tunnel incision was created with a precalibrated knife (Becton Dickinson). A $1.1 \mathrm{~mm}$ (19-gauge) side-port precalibrated knife (Alcon Laboratories, Inc.) was used to create a superior limbal incision 60 to 90 degrees from the former. No direct intracameral injection of epinephrine or phenylephrine was used. A capsulorhexis was created with a forceps after viscomydriasis was obtained, if necessary, using a dispersive or viscoadaptive high-viscosity ophthalmic viscosurgical device (OVD) (sodium hyaluronate 3.0\%-chondroitin sulfate $4.0 \%$ [Viscoat] or sodium hyaluronate $2.3 \%$ [Healon5]). The irrigation fluid consisted of a balanced salt solution with 1:1000000 adrenaline. Disposable iris retractors were applied when significant miosis or billowing followed OVD progressive evacuation with the phaco handpiece. Phacoemulsification was performed with the Sovereign Whitestar machine (Abbott Medical Optics, Inc.) using a 19-gauge phaco tip. Intraocular lens (IOL) implantation was performed through an Unfolder Emerald or Silver injector system (Abbott Medical Optics, Inc.) or through a Monarch II IOL Delivery System (Alcon Italia SpA) without enlarging the tunnel 
incision. The surgical wound was closed by stromal hydration. All patients received topical ofloxacin (Exocin) for 3 days preoperatively and tobramycin-dexamethasone ophthalmic suspension (Tobradex) for 4 weeks postoperatively.

\section{Intraoperative Floppy-Iris Syndrome Grading and Complications}

The severity of IFIS was assessed during OVD phaco aspiration, after removal of iris retractors, and during OVD aspiration with the I/A handpiece. Based on Chang et al., ${ }^{3}$ intraoperative iris behavior was graded as follows: no IFIS (stable normal iris with no significant miosis), mild IFIS (slightly noticeable floppy iris, minor or no miosis, and no tendency of iris prolapse), moderate IFIS (floppy iris, significant miosis and small tendency toward iris prolapse), and severe IFIS (floppy iris, significant miosis, and strong tendency toward iris prolapse). Significant miosis was defined as a $3.0 \mathrm{~mm}$ or more decrease in pupil diameter if mechanical iris devices were used or a $2.0 \mathrm{~mm}$ or more decrease in pupil diameter if no iris devices were used. The surgeon was masked to patient drug history and mydriatic pupil size at the first examination. The occurrence of any sign of IFIS was recorded immediately after surgery.

Intraoperative complications, including posterior capsule rupture, vitreous loss, iris prolapse, iris tears, iris catching by phaco or I/ A tip, iridodialysis, and hyphema, were recorded immediately after surgery. Postoperative complications, such as persistent uveitis, persistent IOP rise, and clinical $\mathrm{CME}$, and iris abnormalities, such as pupil distortion, posterior synechiae, iridodialysis, iris stromal tears, transillumination defects, and permanent mydriasis, were also noted.

\section{Power Calculation and Statistical Analysis}

Based on a power calculation, a sample size of 50 patients per group was determined to allow detection of a minimum clinically relevant difference in pupil diameter of $0.5 \mathrm{~mm}$, with a standard deviation (SD) of 0.6 . The sample size took into account a significance level of $5 \%$ and a power of $80 \%$ for a 2-sided test.

Statistical analysis was performed using Epi Info software (version 3.2.2, U.S. Center for Disease Control and Prevention) and SPSS software (version 14.0, SPSS, Inc.). The results are expressed as the mean \pm SD. Univariate analysis of variance (ANOVA) was used to compare pupil diameters between the groups and post hoc analysis with the Bonferroni test to determine whether there were pairwise differences. Categorical variables were compared using the chi-square test with Yates correction, as needed. Logistic regression analysis was used to evaluate hazard ratios with $95 \%$ confidence intervals (CIs) for IFIS incidence. To assess the predictive rate of different cutoff values of pupil size diameter, a receiver operating characteristic (ROC) curve with calculations of area under the curve and 95\% CIs was constructed and sensitivity, specificity, and accuracy were calculated. All $P$ values were 2 -sided, and $P$ values less than 0.05 were considered to indicate statistical significance.

\section{RESULTS}

The study enrolled 150 patients, 50 in each of the 3 groups. In the other $\alpha_{1}$-ARA group, 15 patients were taking alfuzosin, 15 patients were taking terazosin, and 20 patients were taking doxazosin. Table 1 shows the patient characteristics and pupil size measurements under mesopic low and high conditions and after pharmacologic dilation by group. There was no statistically significant difference in mean age or pupil diameter under mesopic low and mesopic high conditions between the 3 groups. One month before surgery, there was a significant difference between all groups in pupil size after dilation $(P=.001$, univariate ANOVA test). Mydriasis was less in the tamsulosin group than in the other $\alpha_{1}$-ARA group and the no $\alpha_{1}$-ARA group $(P=.033$ and $P=.0003$, respectively, Bonferroni post hoc test). Mydriasis was also less in the other $\alpha_{1}$-ARA group than in the no $\alpha_{1}$-ARA group $(P=.001$, Bonferroni post hoc test). Immediately before surgery, mydriasis differed significantly between all groups $(P<.0005$, univariate ANOVA test). Mydriasis was less in the tamsulosin group than in the other $\alpha_{1}$-ARA group and the no $\alpha_{1}$-ARA group $(P=.0002$ and $P<.0001$, Bonferroni post hoc test). Mydriasis in the other $\alpha_{1}$-ARA group was less than in the no $\alpha_{1}$-ARA group $(P<.0001$, Bonferroni post hoc test).

Table 1. Patient characteristics and pupil size measurements under mesopic low and high conditions and after pharmacologic dilation by group.

\section{Mean $\pm \mathrm{SD}$}

\begin{tabular}{lcccc}
\cline { 2 - 4 } Parameter & Tamsulosin Group & Other $\alpha_{1}$-ARA Group & No $\alpha_{1}$-ARA Group & $P$ Value* \\
\hline Age $(\mathrm{y})$ & $75.2 \pm 6.2$ & $72.5 \pm 5.6$ & $73.8 \pm 10.5$ & \\
Pupil size (mm) & $3.8 \pm 1.1$ & $4.0 \pm 0.7$ & $4.0 \pm 0.9$ & .238 \\
$\quad$ Mesopic low & $2.8 \pm 0.3$ & $2.9 \pm 0.5$ & $3.0 \pm 0.6$ & .326 \\
Mesopic high & $7.1 \pm 1.3$ & $7.6 \pm 1.0$ & $7.9 \pm 0.8$ & .065 \\
1 mo preop & $7.3 \pm 0.4$ & $7.7 \pm 0.6$ & $8.2 \pm 0.2$ & \\
Preop & $6.2 \pm 1.6$ & $6.4 \pm 1.6$ & $7.7 \pm 0.3$ & $<.0005$ \\
Postop & & & & $<.0005$ \\
\hline
\end{tabular}

$\alpha_{1}$-ARA $=\alpha_{1}$-adrenergic receptor antagonist

*Univariate analysis of variance 
Table 2. Frequency of IFIS incidence by group and IFIS grade $(P<.0005)$.*

\begin{tabular}{lcccc}
\hline & & Incidence, $\mathrm{n}(\%)$ & \\
\cline { 2 - 4 } IFIS Grade & Tamsulosin Group & Other $\alpha_{1}$-ARA Group & No $\alpha_{1}$-ARA Group \\
\hline None & $21(42)$ & $33(66)$ & $44(88)$ & $5(10)$ \\
Mild & $12(24)$ & $3(6)$ & $1(2)$ & $98(65)$ \\
Moderate & $13(26)$ & $14(28)$ & 0 & $20(13)$ \\
Severe & $4(8)$ & 0 & & $4(3)$ \\
\hline$\alpha_{1}$-ARA $=\alpha_{1}$-adrenergic receptor antagonist; IFIS = intraoperative floppy-iris syndrome & & \\
*Chi-square test with Yates correction & & \\
\hline
\end{tabular}

Postoperatively, there were significant differences in pupil size between the 3 groups $(P<.0005$, univariate ANOVA test); the pupil size was smaller in the tamsulosin group and the other $\alpha_{1}$-ARA group than in the no $\alpha_{1}$-ARA group $(P<.0005$, Bonferroni post hoc test). No difference was found between the tamsulosin group and the other $\alpha_{1}$-ARA group.

There were a total of 52 cases of IFIS, $29(58 \%)$ in the tamsulosin group, $17(34 \%)$ in the other $\alpha_{1}$-ARA group, and $6(12 \%)$ in the no $\alpha_{1}$-ARA group. Table 2 shows the frequency of IFIS by group and IFIS grade; the frequency differed significantly between all the groups $\left(P<.0005\right.$, Pearson $\chi^{2}$ test). The incidence of overall IFIS (Table 3 ) differed significantly between the tamsulosin group and the no $\alpha_{1}$-ARA group $(P<.0005$, Yates corrected chi square), between the other $\alpha_{1}$-ARA group and the no $\alpha_{1}$-ARA group $\left(P=.017\right.$, Yates corrected $\left.\chi^{2}\right)$, and between the tamsulosin group and the other $\alpha_{1}$-ARA group $(P=.027$; Yates corrected $\chi^{2}$ ) (Table 3). Further, regression analysis found a hazard ratio for IFIS of 10.1 (95\% CI, 3.6-28.1; $P<.0005)$ for tamsulosin and a hazard ratio of 3.8 (95\% CI, 1.3-10.6; $P=.012)$ for other $\alpha_{1}$-ARAs. No statistically significant differences were found in pupil size, any condition, or the occurrence of IFIS

Table 3. Frequency of overall IFIS incidence by group $(P=<.0005)$.

\begin{tabular}{|c|c|c|c|}
\hline \multirow[b]{2}{*}{ Group } & \multicolumn{2}{|c|}{ Frequency, n (\%) } & \multirow[b]{2}{*}{$P$ Value* } \\
\hline & No IFIS & $\begin{array}{l}\text { Overall IFIS (Mild, } \\
\text { Moderate, Severe) }\end{array}$ & \\
\hline No $\alpha_{1}$-ARA & $44(88)$ & $6(12)$ & - \\
\hline Other $\alpha_{1}$-ARA & $33(66)$ & $17(34)$ & $.017^{\dagger}$ \\
\hline Tamsulosin & $21(42)$ & $29(58)$ & $\begin{array}{c}<.0005^{\dagger} \\
.027^{\ddagger}\end{array}$ \\
\hline \multicolumn{4}{|c|}{$\begin{array}{l}\alpha_{1} \text {-ARA }=\alpha_{1} \text {-adrenergic receptor antagonist; IFIS }=\text { intraoperative } \\
\text { floppy-iris syndrome } \\
{ }^{*} \text { Chi-square test with Yates correction } \\
{ }^{\dagger} \text { Versus no } \alpha 1 \text { ARA group } \\
{ }^{\ddagger} \text { Versus other } \alpha 1 \text { ARA group }\end{array}$} \\
\hline
\end{tabular}

between the other $\alpha_{1}$-ARA subgroups (ie, alfuzosin, terazosin, and doxazosin).

Pupil size after pharmacologic dilation 1 month before surgery, after preoperative dilation, and postoperatively correlated with the incidence of IFIS $(P<.0005$, univariate ANOVA test) (Table 4). Post hoc analysis indicated that pupil size was inversely related to overall IFIS incidence and to IFIS severity (Table 4). The ROC curve analysis using the dilated pupil measurement showed that a pupil $7.0 \mathrm{~mm}$ or smaller predicted IFIS with 73\% sensitivity (95\% CI, 70\%-84\%) and 95\% specificity (95\% CI, 89\%-98\%) $(P=.0001)$ (Figure 1$)$. The ROC curve subanalysis for IFIS severity indicated that a dilated pupil smaller than $7.0 \mathrm{~mm}$ was predictive of moderate IFIS (sensitivity $86 \%$ : 95\% CI, 70\%96; $P=.0001$ ) (specificity 90\%: 95\% CI, 83\%-95\%; $P=.0001$ ) and severe IFIS (sensitivity 96\%: 95\% CI, 75\%-98\%; $P=.0001$ ) (specificity 90\%: 95\% CI, $75 \%-96 \% ; P=.0001)$ but not of mild IFIS. The overall diagnostic accuracy of IFIS prediction by pupil size evaluation using the $7.0 \mathrm{~mm}$ threshold was $85 \%$.

Few intraoperative complications occurred. Disposable iris retractors were used in 10 patients $(20 \%)$ in the tamsulosin group, 7 patients $(14 \%)$ in the other $\alpha_{1}$ ARA group, and 1 patient $(2 \%)$ in the no $\alpha_{1}$-ARA group. Momentary aspiration of the iris with the phaco tip was uncommon because of prompt application of iris retractors. Focal iris stromal atrophy caused by retractors or prolapse was a common occurrence. No patient had an irregular or permanently dilated pupil as a result of surgical iris sphincter trauma. Three patients had a capsulorhexis tear during phacoemulsification; however, the IOL was successfully implanted in the capsular bag in all cases. There were no cases of intraocular hemorrhage, posterior capsule rupture, or vitreous loss. On the first postoperative day, 28 eyes $(18.6 \%)$ had a transient IOP elevation over $22 \mathrm{~mm} \mathrm{Hg}$; no patient had protracted IOP elevation. In the early postoperative period, clinical CME was present in 3 cases ( $2 \%)$. The corrected distance visual acuity was 20/40 or better in all eyes at the 1-month follow-up visit. 
Table 4. Relationship between pupil-size measurements after dilation and IFIS grade.

\begin{tabular}{|c|c|c|c|c|c|c|c|c|c|c|c|}
\hline \multirow[b]{2}{*}{ Exam } & \multicolumn{4}{|c|}{ IFIS Grade } & \multicolumn{7}{|c|}{$P$ Value* } \\
\hline & No IFIS & $\begin{array}{l}\text { Mild } \\
\text { IFIS }\end{array}$ & $\begin{array}{l}\text { Moderate } \\
\text { IFIS }\end{array}$ & $\begin{array}{l}\text { Severe } \\
\text { IFIS }\end{array}$ & Overall & $\begin{array}{l}\text { No Vs } \\
\text { Mild }\end{array}$ & $\begin{array}{l}\text { No Vs } \\
\text { Moderate }\end{array}$ & $\begin{array}{l}\text { No Vs } \\
\text { Severe }\end{array}$ & $\begin{array}{l}\text { Mild Vs } \\
\text { Moderate }\end{array}$ & $\begin{array}{l}\text { Mild Vs } \\
\text { Severe }\end{array}$ & $\begin{array}{c}\text { Moderate Vs } \\
\text { Severe }\end{array}$ \\
\hline $\begin{array}{l}1 \mathrm{mo} \\
\text { preop }\end{array}$ & $7.8 \pm 0.9$ & $7.1 \pm 0.7$ & $7.1 \pm 1.4$ & $5.2 \pm 0.2$ & $<.0005$ & .024 & .006 & .0005 & - & .002 & .001 \\
\hline Preop & $7.7 \pm 0.3$ & $7.2 \pm 0.6$ & $6.9 \pm 0.4$ & $6.5 \pm 0.2$ & $<.0005$ & $<.0005$ & $<.0005$ & $<.0005$ & .016 & .004 & - \\
\hline Postop & $7.5 \pm 0.7$ & $5.9 \pm 1.3$ & $5.2 \pm 1.0$ & $3.0 \pm 0.3$ & $<.0005$ & $<.0005$ & $<.0005$ & $<.0005$ & .05 & $<.0005$ & $<.0005$ \\
\hline
\end{tabular}

\section{DISCUSSION}

Cataract extraction is one of the most frequently performed surgeries in developed countries. ${ }^{23}$ Adequate pupil dilation and subsequent stability of the iris during surgery are key to successful and safe phacoemulsification. ${ }^{24}$

As stated, IFIS can increase the risk for intraoperative complications if not identified and managed early in otherwise uncomplicated cataract surgery. $1,3,4$ The importance of predicting IFIS before phacoemulsification becomes evident when reviewing surgical complications in the peer-reviewed literature. Early retrospective studies of IFIS showed posterior capsule rupture rates of $7 \%{ }^{13}$ to $12 \% .{ }^{1}$ Prospective data collected by Chang and Campbell ${ }^{1}$ and Chang et al. ${ }^{3}$ after

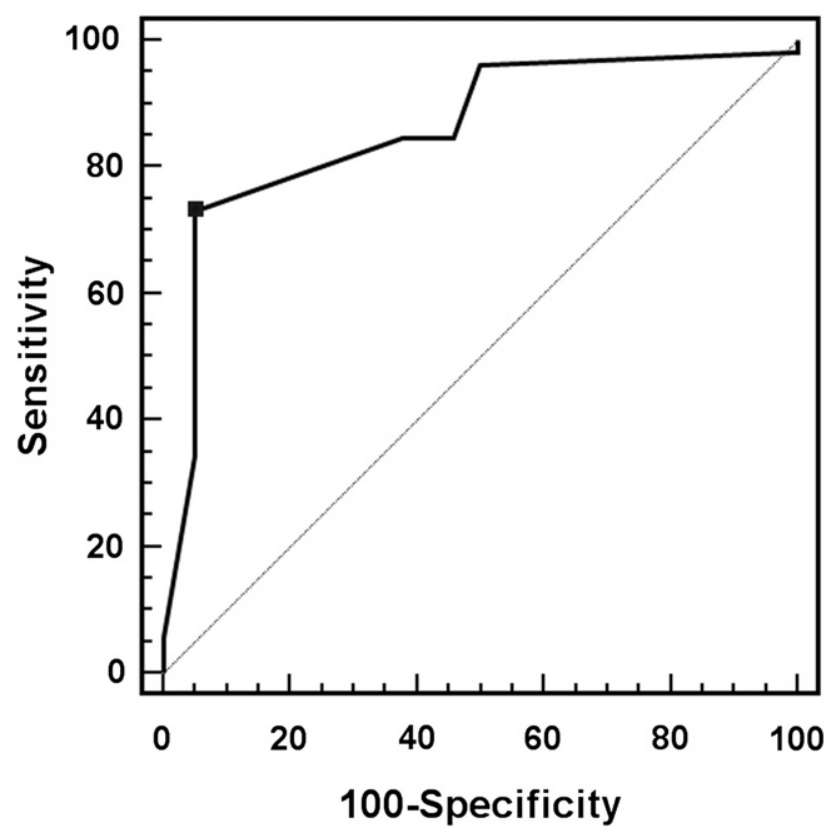

Figure 1. The ROC curve for determination of predictive value of pupil size measurement after dilation for IFIS incidence (area under the curve $=0.859$ ). the characteristics of IFIS had been well defined and management techniques had been explored showed a reduction in the posterior capsule rupture rate to zero. From these studies, it is evident that an understanding of this important clinical syndrome makes a significant difference in whether IFIS will lead to intraoperative complications. This also points to the need to identify all risk factors involved in IFIS. ${ }^{8,12}$

In high-volume cataract surgery units, especially those with less experienced surgeons, IFIS prediction and recognition are especially important. In a study of cataract extractions performed by resident physicians, the reported incidence of posterior capsule rupture and vitreous loss was $7.4 \%$ in patients taking tamsulosin compared with $1.8 \%$ in patients not taking tamsulosin. $^{22}$ Even for experienced surgeons, the rate of vitreous loss during cataract surgery in patients taking tamsulosin ranges from $0.6 \%$ for high-volume surgeons to $7.0 \%$ and $12.0 \%$ in United States and United Kingdom surveys, respectively. ${ }^{1,13,21,22}$ However, when IFIS is anticipated and proper management strategies are used, the outcome is favorable and the complication rate is low for both skilled surgeons and residents. $3,22,25$

The present study found no difference in pupil diameter under mesopic conditions between patients on tamsulosin, patients on another $\alpha_{1}$-ARA, or patients on no $\alpha_{1}$-ARA. This may be due to the complexity of the biology of the aging iris in which multiple factors affect pupil functionality and could overcome the $\alpha_{1}$-ARA effect. For instance, the pupil decreases in size with advanced age, independent of a mydriatic effect. $^{11,26}$ In general, medical conditions associated with endothelial dysregulation (eg, congestive heart failure, diabetes, hypertension) have the potential to affect iris integrity. ${ }^{11}$

However, the pharmacologic induction of mydriasis in this study was adequate to show the effect of $\alpha_{1}$-ARAs, in particular tamsulosin, on iris smooth musculature, with a reduction in the mydriatic 
response in patients on $\alpha_{1}$-ARAs compared with patients not on $\alpha_{1}$-ARAs. This was true with the standard protocol for mydriasis induction and with the heavier preoperative instillation of mydriatics plus topical lidocaine, whose mydriatic effect is known. ${ }^{27}$ At the end of surgery, patients taking $\alpha_{1}$-ARAs had clearly reduced pupil diameters compared with those not taking $\alpha_{1}$-ARAs. A difference between tamsulosin and other $\alpha_{1}$-ARAs was not found; however, the higher rates of surgical trauma and use of mechanical iris retractors in these groups could have masked a difference.

The overwhelming majority of IFIS cases in the present study were in patients on $\alpha_{1}$-ARA treatment, with severe cases found only in the tamsulosin group $(8 \%$ of the group). Our results agree with those in the literature, in which the reported incidence of IFIS ranges from $43 \%$ to $100 \%$ in patients treated with tamsulo$\sin .{ }^{1,2,4,15,28}$ The greater incidence and severity of IFIS in our tamsulosin group than in the other $\alpha 1$-ARA group is supported by the findings in the ASCRS survey ${ }^{21}$ and is in agreement with the hypothesis that the systemic use of less selective $\alpha_{1 \mathrm{~A}}$-subtype antagonists leads to a lower prevalence of IFIS. ${ }^{1,15,28,29}$ A recent study from Canada ${ }^{4}$ reports an adjusted odds ratio of 32 for IFIS in patients exposed to tamsulosin compared with those exposed to alfuzosin. Another study based on an animal model found that the plasma concentration of tamsulosin antagonized pupil dilation, whereas that of alfuzosin did not. ${ }^{25}$

Chang et al. ${ }^{3}$ and Chang ${ }^{30}$ found that IFIS was less common and less severe in patients taking nonselective $\alpha$ blockers, such as alfuzosin, doxazosin, and terazosin. It is not clear why nonselective $\alpha_{1}$-ARAs inhibit pharmacologic mydriasis in humans but are not strongly associated with IFIS. However, prostate binding studies clearly show that these drugs have different receptor-affinity profiles than tamsulosin. ${ }^{6,31}$

The mainly mild IFIS in $12 \%$ of patients in our no $\alpha_{1}$-ARA group is not surprising when data in the literature are analyzed. For example, $36 \%$ of respondents in the ASCRS survey noted IFIS with drugs other than $\alpha_{1}$-ARAs. ${ }^{21}$ Drugs that have been associated with IFIS include saw palmetto, an herbal supplement used for $\mathrm{BPH}$; finasteride; antipsychotic drugs; and some $\beta$-blockers with particular $\alpha$-blocking properties. ${ }^{12,21,32-35}$ Other drugs that might induce iris dilator smooth-muscle relaxation include endothelin-A antagonists, angiotensin antagonists, and nitric oxide donor compounds. ${ }^{8,11}$

Certain systemic diseases, such as diabetes, hypertension, and congestive heart failure, can affect intraoperative iris behavior. ${ }^{11,12}$ Schwinn and Afshari ${ }^{11}$ hypothesize that because of the complexity of signaling pathways in the iris, $\alpha_{1}$-ARAs are merely the beginning of our understanding of IFIS and that a constellation of factors more complex than previously thought affects the causes of IFIS.

Our results on the pupillary mydriatic response with IFIS incidence and severity in various patient groups are dependent on the mydriatic regimen chosen and irrigation with balanced salt solution containing adrenaline. Alternative management strategies, such as preoperative topical nonsteroidal antiinflammatory drugs, cyclopentolate, atropine, intracameral epinephrine, or pupil expansion rings, could yield different results. These factors, together with the surgeon's subjective perception of the degree of severity of IFIS, especially in mild cases, may help explain the widely variable incidences and severity of IFIS reported in the literature. ${ }^{3,21,22}$

With respect to IFIS prediction by pharmacologically dilated pupil size, such a possibility seems viable on the basis of our results. In general, preoperative and postoperative measurements taken with computerized pupillometer or calipers appear to be inversely related to the incidence and severity of IFIS. The results in this prospective study agree with the retrospective data from Chen et al. ${ }^{22}$ in patients taking tamsulosin, which showed that the incidence of IFIS, regardless of severity, was higher in eyes with smaller preoperative dilated pupils. The high sensitivity (73\%) and specificity $(95 \%)$ in our ROC curve analysis confirm the value of the $7.0 \mathrm{~mm}$ dilated pupil threshold in identifying patients at risk for moderate or severe IFIS. Our ROC curve analysis results indicate that with a pupil diameter of $7.0 \mathrm{~mm}$ or less, not only patients taking $\alpha_{1}$-ARAs but even those not taking $\alpha_{1}$-ARAs are at risk for IFIS, with high diagnostic accuracy. The degree of the risk in a patient not taking $\alpha_{1}$-ARAs is probably bound to the complex constellation of factors described above. For instance, the incorporation of saw palmetto into multivitamin formulations is becoming common, and the widespread use of multivitamins makes it difficult to quantify the actual incidence of saw palmetto use by the general population. It is therefore conceivable that undocumented use of saw palmetto could be the cause in IFIS cases with no clearly associated factors. ${ }^{8,12}$ Moreover, the possibility cannot be excluded that the patients who had IFIS in the control group could have been exposed to tamsulosin in the past but they had no accurate memory to report to the investigators. The rate of complications in this study was within the limits previously reported for high-volume experienced surgeons and similar to the reported rate after standard phacoemulsification with IOL implantation. 3,22,36,37

This study had several limitations, including the small number of events per variable. Peduzzi et al. ${ }^{38}$ recommend a model that include a minimum of 10 
events per variable. Although the power and sample size calculations were performed and their requirements exceeded, this study would have benefited from a larger sample. Because of the limited sample size, we cannot draw firm conclusions about the incidence of IFIS in the subgroups of patients taking different nonselective $\alpha_{1 \mathrm{~A}}$-subtype antagonists; therefore, our data are not suitable to differentiate the effect of alfuzosin, terazosin, and doxazosin. Also, given the nature of IFIS as an intraoperative surgical phenomenon, this study relied on the surgeon's subjective assessment of IFIS, which could have been influenced by the immediate preoperative pupil size.

In conclusion, this study confirmed inhibition of pupil pharmacologic dilation by various $\alpha_{1}$-ARAs, in particular tamsulosin. The ROC curves indicate that dilated pupil size can predict IFIS risk and severity. Therefore, careful dilated-pupil measurements should become part of preoperative protocol in preparation for surgery. A dilated pupil of $7.0 \mathrm{~mm}$ or smaller in a patient not affected by diabetes, glaucoma, or pseudoexfoliation increases the risk for IFIS, even without a clear history of $\alpha_{1}$-ARA administration. In such cases, the surgeon should supplement the informed consent process and consider perioperative strategies (atropine eyedrops, epinephrine for intracameral injection or in the irrigation solution, viscoadaptive or a soft-shell technique, iris retractors or pupil expansion rings). Furthermore, patients using an $\alpha_{1}$-ARA should be operated on by experienced surgeons who have the judgment on whether to make relevant changes in the procedure and on managing preoperative or intraoperative preventive strategies. ${ }^{8,39}$ In countries with large elderly populations, it is important to pursue identification of other factors, by further studies, that put patients at risk for IFIS.

\section{REFERENCES}

1. Chang DF, Campbell JR. Intraoperative floppy iris syndrome associated with tamsulosin. J Cataract Refract Surg 2005; 31:664673

2. Pärssinen $O$. The use of tamsulosin and iris hypotony during cataract surgery [letter]. Acta Ophthalmol Scand 2005; 83:625626. Available at: http://onlinelibrary.wiley.com/doi/10.1111/j. 1600-0420.2005.00512.x/pdf. Accessed March 21, 2011

3. Chang DF, Osher RH, Wang L, Koch DD. Prospective multicenter evaluation of cataract surgery in patients taking tamsulosin (Flomax). Ophthalmology 2007; 114:957-964

4. Blouin MC, Blouin J, Perreault S, Lapointe A, Dragomir A. Intraoperative floppy iris syndrome associated with $\alpha_{1}$-adrenoreceptors; comparison of tamsulosin and alfuzosin. J Cataract Refract Surg 2007; 33:1227-1234

5. Pärssinen $O$, Leppänen E, Keski-Rahkonen $P$, Mauriala $T$, Dugué B, Lehtonen M. Influence of tamsulosin on the iris and its implications for cataract surgery. Invest Ophthalmol Vis Sci 2006; 47:3766-3771. Available at: http://www.iovs.org/cgi/ reprint/47/9/3766. Accessed March 21, 2011
6. Roehrborn CG, Schwinn DA. $\alpha_{1}$-adrenergic receptors and their inhibitors in lower urinary tract symptoms and benign prostatic hyperplasia. J Urol 2004; 171:1029-1035

7. AUA Practice Guidelines Committee. AUA guideline on management of benign prostatic hyperplasia (2003). Chapter 1: diagnosis and treatment recommendations. J Urol 2003; 170:530-547

8. Abdel-Aziz S, Mamalis N. Intraoperative floppy iris syndrome. Curr Opin Ophthalmol 2009; 20:37-41

9. Parmar B, Qatarneh D, Claoué C. Alpha antagonists in cataract surgery [letter]. J Cataract Refract Surg 2005; 31:2241; reply by DF Chang, JR Campbell, 2241

10. Leonardi A, Hieble JP, Guarneri L, Naselsky DP, Poggesi E, Sironi G, Sulpizio AC, Testa R. Pharmacological characterization of the uroselective alpha-1 antagonist Rec 15/2739 (SB 216469): role of the alpha-1L adrenoceptor in tissue selectivity, part I. J Pharmacol Exp Ther 1997; 281:1272-1283. Available at: http://jpet.aspetjournals.org/content/281/3/1272.full.pdf. Accessed March 21, 2011

11. Schwinn DA, Afshari NA. $\alpha_{1}$-adrenergic receptor antagonists and the iris: new mechanistic insights into floppy iris syndrome. Surv Ophthalmol 2006; 51:501-512

12. Neff KD, Sandoval HP, Fernández de Castro LE, Nowacki AS, Vroman DT, Solomon KD. Factors associated with intraoperative floppy iris syndrome. Ophthalmology 2009; 116:658-663

13. Nguyen DQ, Sebastian RT, Kyle G. Surgeon's experiences of the intraoperative floppy iris syndrome in the United Kingdom [letter]. Eye 2007; 21:443-444. Available at: http://www.nature. com/eye/journal/v21/n3/pdf/6702616a.pdf. Accessed March 21,2011

14. Cheung CMG, Awan MAR, Sandramouli S. Prevalence and clinical findings of tamsulosin-associated intraoperative floppy-iris syndrome. J Cataract Refract Surg 2006; 32:1336-1339

15. Chadha V, Borooah S, Tey A, Styles C, Singh J. Floppy iris behaviour during cataract surgery: associations and variations. $\mathrm{Br}$ J Ophthalmol 2007; 91:40-42. Available at: http://www.ncbi. nlm.nih.gov/pmc/articles/PMC1857591/pdf/40.pdf. Accessed March 21, 2011

16. Schwinn DA, Afshari NA. $\alpha_{1}$-adrenergic antagonists and floppy iris syndrome: tip of the iceberg? [editorial]. Ophthalmology 2005; 112:2059-2060

17. EI-Ghatit AM. Association of IFIS and vasodepressor medication [letter]. J Cataract Refract Surg 2006; 32:546-547

18. Settas G, Fitt AW. Intraoperative floppy iris syndrome in a patient taking alfuzosin for benign prostatic hypertrophy [letter]. Eye 2006; 20:1431-1432. Available at: http://www.nature.com/eye/ journal/v20/n12/pdf/6702291a.pdf. Accessed March 21, 2011

19. Muqit MMK, Menage MJ. Intraoperative floppy iris syndrome [letter]. Ophthalmology 2006; 113:1885-1886; reply by DA Schwinn, NA Afshari, 1886

20. Srinivasan S, Radomski S, Chung J, Plazker T, Singer S, Slomovic AR. Intraoperative floppy-iris syndrome during cataract surgery in men using alpha-blockers for benign prostatic hypertrophy. J Cataract Refract Surg 2007; 33:1826-1827

21. Chang DF, Braga-Mele R, Mamalis N, Masket S, Miller KM, Nichamin LD, Packard RB, Packer M; for the ASCRS Cataract Clinical Committee. Clinical experience with intraoperative floppy-iris syndrome; results of the 2008 ASCRS member survey. J Cataract Refract Surg 2008; 34:1201-1209

22. Chen AA, Kelly JP, Bhandari A, Wu MC. Pharmacologic prophylaxis and risk factors for intraoperative floppy-iris syndrome in phacoemulsification performed by resident physicians. J Cataract Refract Surg 2010; 36:898-905 
23. Hall MJ, Lawrence L. Ambulatory surgery in the United States, 1996. Adv Data 1998; 300:1-16. Available at: http://www.cdc. gov/NCHS/data/ad/ad300.pdf. Accessed March 21, 2011

24. Lumme P, Laatikainen LT. Risk factors for intraoperative and early postoperative complications in extracapsular cataract surgery. Eur J Ophthalmol 1994; 4:151-158

25. Palea S, Chang DF, Rekik M, Regnier A, Lluel P. Comparative effect of alfuzosin and tamsulosin on the contractile response of isolated rabbit prostatic and iris dilator smooth muscles; possible model for intraoperative floppy-iris syndrome. J Cataract Refract Surg 2008; 34:489-496

26. Buckley C, Curtin DM, Docherty J, Eustace P. Ageing and alpha adrenoceptors in the iris. Eye 1987; 1:211-216

27. Claesson M, Johansson M, Behndig A. Mydriasis with different preparations of topically administered lidocaine hydrochloride. J Cataract Refract Surg 2009; 35:277-281

28. Oshika T, Ohashi Y, Inamura M, Ohki K, Okamoto S, Koyama T, Sakabe I, Takahashi K, Fujita Y, Miyoshi T, Yasuma T. Incidence of intraoperative floppy iris syndrome in patients on either systemic or topical $\alpha_{1}$-adrenoceptor antagonist. Am J Ophthalmol 2007; 143:150-151

29. Chang DF, Campbell JR. Intraoperative floppy-iris syndrome associated with tamsulosin [reply to letter by RM Kershner]. J Cataract Refract Surg 2005; 31:2239-2240

30. Chang DF. Floppy iris syndrome: why BPH treatment can complicate cataract surgery [editorial]. Am Fam Physician 2009; 79:1051-1056. Available at: http://www.aafp.org/afp/2009/ 0615/p1051a.html. Accessed March 21, 2011

31. Lowe F. Alpha-1-adrenoceptor blockade in the treatment of benign prostatic hyperplasia. Prostate Cancer Prostatic Dis 1999;
2:110-119. Available at: http://www.nature.com/pcan/journal/ v2/n3/pdf/4500302a.pdf. Accessed March 22, 2011

32. Issa SA, Dagres E. Intraoperative floppy-iris syndrome and finasteride intake. J Cataract Refract Surg 2007; 33:2142-2143

33. Ünal M, Yücel I, Tenlik A. Intraoperative floppy-iris syndrome associated with chronic use of chlorpromazine [letter]. Eye 2007; 21:1241-1242. Available at: http://www.nature.com/eye/ journal/v21/n9/pdf/6702914a.pdf. Accessed March 22, 2011

34. Ugarte $\mathrm{M}$, Leong $\mathrm{T}$, Rassam S, Kon $\mathrm{CH}$. Intraoperative floppyiris syndrome, $\alpha_{1}$-adrenergic antagonists, and chronic intake of mianserin: is there an association? J Cataract Refract Surg 2007; 33:170

35. Calotti F, Steen D. Labetalol causing intraoperative floppy-iris syndrome. J Cataract Refract Surg 2007; 33:170-171

36. Takmaz T, Can I. Intraoperative floppy-iris syndrome: do we know everything about it? J Cataract Refract Surg 2007; 33:1110-1112

37. Lundström M, Barry P, Leite E, Seward H, Stenevi U. 1998 European Cataract Outcome Study; report from the European Cataract Outcome Study Group. J Cataract Refract Surg 2001; 27:1176-1184

38. Peduzzi P, Concato J, Kemper E, Holford TR, Feinstein AR. A simulation study of the number of events per variable in logistic regression analysis. J Clin Epidemiol 1996; 49:1373-1379

39. Storr-Paulsen A, Nørregaard JC, Børme KK, Larsen AB, Thulesen J. Intraoperative floppy iris syndrome (IFIS): a practical approach to medical and surgical considerations in cataract extractions. Acta Ophthalmol (Oxf) 2009; 87:704-708. Available at: http://onlinelibrary.wiley.com/doi/10.1111/j.1755-3768.2008. 01442.x/pdf. Accessed March 22, 2011 